\title{
A decision tree model for the prediction of homodimer folding mechanism
}

\author{
1,2 \\ Abishek Suresh ${ }^{1,2}$, Velmurugan Karthikraja , Sajitha Lulu , Uma Kangueane , Pandjassarame Kangueane \\ Biomedical Informatics, Pondicherry 607402, ${ }^{2}$ AIMST University, Semeling 08100, Malaysia; Pandjassarame Kangueane - E-mail: \\ kangueane@bioinformation.net; Phone: +91 4132633 589; Fax: +91 4132633 722; *Corresponding author
}

Abstract:

Received October 20, 2009; Accepted November 09, 2009; Published November 17, 2009

The formation of protein homodimer complexes for molecular catalysis and regulation is fascinating. The homodimer formation through $2 \mathrm{~S}$ (2 state), 3SMI (3 state with monomer intermediate) and 3SDI (3 state with dimer intermediate) folding mechanism is known for 47 homodimer structures. Our dataset of forty-seven homodimers consists of twenty-eight 2S, twelve 3SMI and seven 3SDI. The dataset is characterized using monomer length, interface area and interface/total (I/T) residue ratio. It is found that 2S are often small in size with large I/T ratio and 3SDI are frequently large in size with small I/T ratio. Nonetheless, 3SMI have a mixture of these features. Hence, we used these parameters to develop a decision tree model. The decision tree model produced positive predictive values (PPV) of $72 \%$ for $2 \mathrm{~S}$, $58 \%$ for 3SMI and 57\% for 3SDI in cross validation. Thus, the method finds application in assigning homodimers with folding mechanism.

Keywords: folding, homodimer, decision tree, prediction, mechanism

\section{Background:}

Homodimers play an important role in catalysis and regulation. The formation of homodimer interface is structurally intriguing [1]. The mechanism of formation of such homodimer interfaces is further appealing. Structures for 47 homodimers with known folding information are now available as given in Table 1 (supplementary material) [2-46]. These homodimers are formed through 2-sate (2S) [2-28], or 3-state with monomer intermediate (3SMI) [36-46] or 3state with dimer intermediate (3SDI) [29-35]. A couple of homodimers have been described as cancer targets [47, 48, 49]. Hence, the future definition of homodimers as drug targets is evident. Therefore, it is important to understand both homodimer association and its folding mechanism of formation. A number of attempts have been made to relate homodimer structures to folding mechanism to decipher folding specific structural features [50-54]. We recently documented the relationship between structural features describing homodimer folding mechanism [55]. Nevertheless, folding information on homodimers is far less than the known number of homodimer structures stored in databases [1]. Therefore, it is of interest to predict folding mechanism to known homodimer structures. We created an improved dataset of 47 homodimer structures from PDB with known folding mechanism to glean parameters and to develop models for homodimer folding mechanism prediction given their structures. We then use these parameters to design a decision tree model to classify homodimer structures with unknown folding mechanism.

Methodology:

Dataset:

We created a dataset of 47 homodimer structures from PDB with known folding information taken from respective literature (Table 1 in supplementary material). The dataset consists of twenty eight 2S, twelve 3SMI and seven 3SDI structures. Table 1 (see supplementary material) also provides information on structural parameters such as monomer length (ML), interface area (B/2) and interface to total residue $(\mathrm{I} / \mathrm{T})$ ratio for each structure. The structural features in the dataset are summarized in Table 2 (see supplementary material).

\section{Monomer length (ML):}

Monomer length (ML) refers to the protein length of monomers forming the homodimer complex. The distribution of 2S, 3SMI and 3SDI with ML is shown in Figure 1a. The figure illustrates the minimum and maximum limits of ML for 2S, 3SMI and 3SDI homodimers in the dataset. The length of $2 \mathrm{~S}$ proteins are found in the range of 45 to 271 , 3SMI in the range of 72 and 381, while 3SD between 90 and 835 . There is some degree of ML overlap between the three categories of homodimers.

\section{Interface area $(\mathrm{B} / \mathbf{2})$ :}

Interface area $(B / 2)$ is defined as the change in accessible surface area (delta ASA) when going from monomer state to dimer state during complex formation. Accessible surface area (ASA) is calculated using the software SURFACE RACER 5.0 [56] using the algorithm described by Lee and Richard [56]. The distribution of 2S, 3SMI and 3SDI with B/2 is shown in Figure 1b. The figure shows the graphical representation of homodimers according to their interface area. 2S proteins have B/2 range between 156 -2507 $\AA^{2}$ and 3SMI proteins range within 309 and $2317 \AA^{2}$. However, 3SDI dimers lie between 1351 and $2317 \AA^{2}$.

Interface to total residue (I/T) ratio:

It is the ratio between the numbers of interface residues per monomer (residues involved in homodimer interactions at the interface) to the total number of residues in monomer protein. Interface residues are identified using ASA calculation described in previous section. The distribution of 2S, 3SMI and 3SDI with I/T ratio is shown in Figure 1c. The figure shows the graphical representation of homodimers to I/T ratio. Here, the 3SDI proteins lie in the range of 5 to $50 \%$, and 3SMI in the range of 9 to $44 \%$, while the $2 \mathrm{~S}$ proteins lie in the range of 6 to $80 \%$.

Decision tree model:

A decision model is a clear logical model that can be easily understood by persons who are not mathematically inclined. The decision tree model is a classification tree to classify the target variable (folding mechanism in this case) based on the predictor variables $(\mathrm{ML}, \mathrm{B} / 2$ and $\mathrm{I} / \mathrm{T}$ ) described in previous sections. The cumulative frequencies of the three predictors $(\mathrm{ML}, \mathrm{B} / 2$ and $\mathrm{I} / \mathrm{T}$ ) were used to decide the values in the logical conditions of the decision tree. A flowchart describing the decision tree model is illustrated in Figure 3. The model checks for ML, I/T and B/2 for each known homodimer structures to assign their folding mechanism using human expert cut-off values as shown in Figure 3.

\section{Validation:}

An internal cross validation is performed for 47 homodimers in Table 1 using the decision tree model described above. The results of the validation using true positive (TP), false positive (FP) and positive predictive value (PPV) is given in Table 5. PPV (\%) is defined as $\mathrm{TP} /(\mathrm{TP}+\mathrm{FP}) * 100$.

\section{Assignment dataset:}

We created a dataset of 149 homodimers with unknown folding information for prediction and assignment of folding mechanism using structural parameters (Table 3 in supplementary material). The structural features in the dataset are summarized in Table 4 (see supplementary material). A classification of 149 homodimers into three target categories using the decision tree model is given in Table 6 (see supplementary material). 

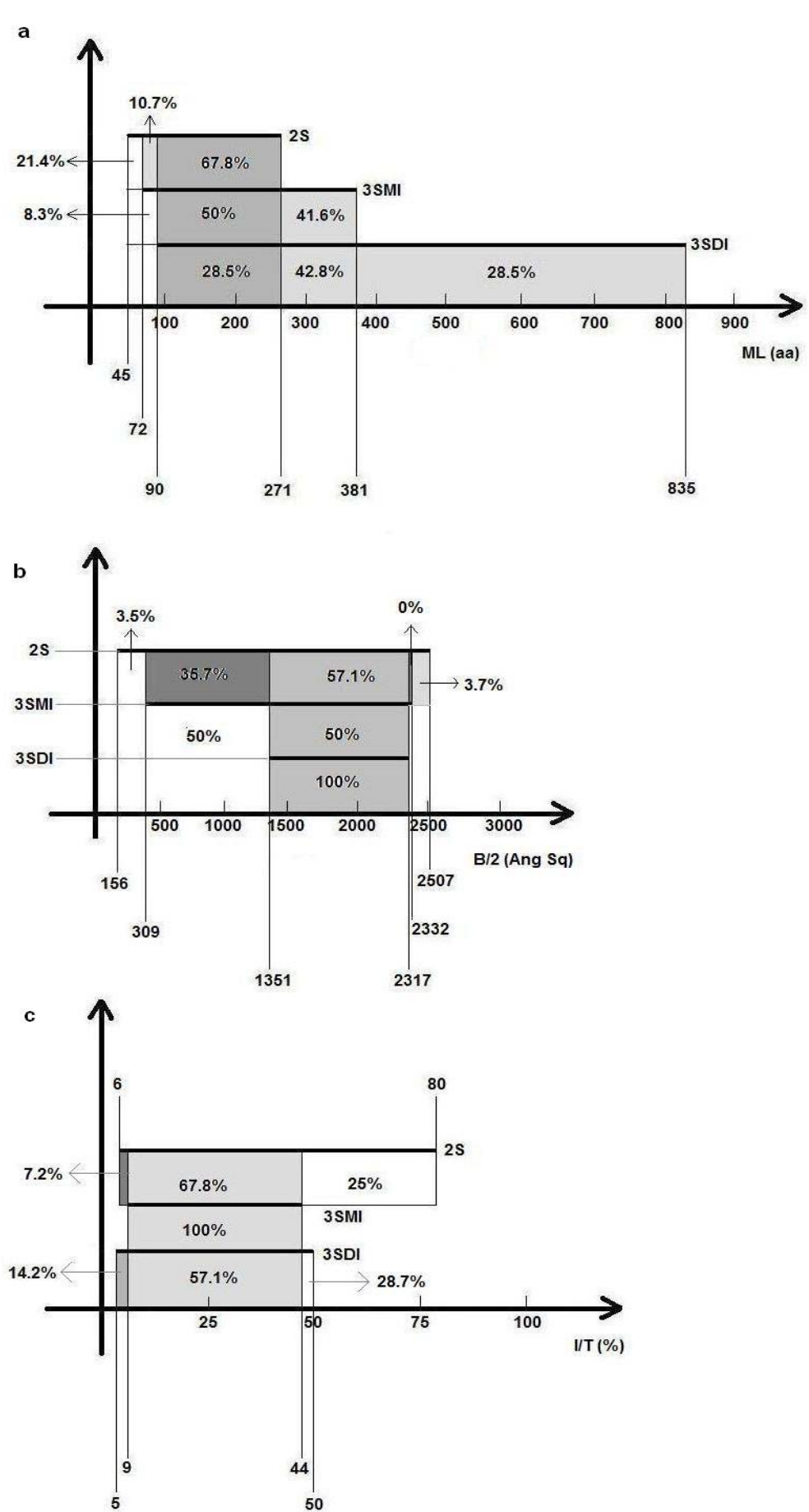

Figure 1: Distribution of 2S, 3SMI and 3SDI for ML, B/2 and I/T is shown. (a) An illustration of the minimum and maximum limits of ML for 2S, 3SMI and 3SDI homodimers in the dataset is presented. The $\mathrm{X}$ - axis represents monomer length. The overlap regions are shown horizontally. 2S proteins range from 45 to 271, 3SMI range from 72 to 381 and 3SDI range from 90 to 835 . (b) An illustration of the minimum and maximum limits of ML for 2S, 3SMI and 3SDI homodimers in the dataset is presented. The X - axis represents interface area. The overlap regions are shown horizontally. 2S proteins range from 156 to 2507, 3SMI range from 309 to 2332 and 3 SDI range from 1351 to 2317. (c) Distribution of 2S, 3SMI and 3SDI for I/T ratio. An illustration of the minimum and maximum limits of I/T for 2S, 3SMI and 3SDI homodimers in the dataset is presented. The $\mathrm{X}$ - axis represents $\mathrm{I} / \mathrm{T}$ ratio. The overlap regions are shown horizontally. $2 \mathrm{~S}$ proteins range from 6 to 80, 3SMI range from 9 to 44 and 3SDI range from 5 to 50. It should be noted that there is no Y-axis variable defined in this case. However, a Y-axis is shown for convenience of visualization. 

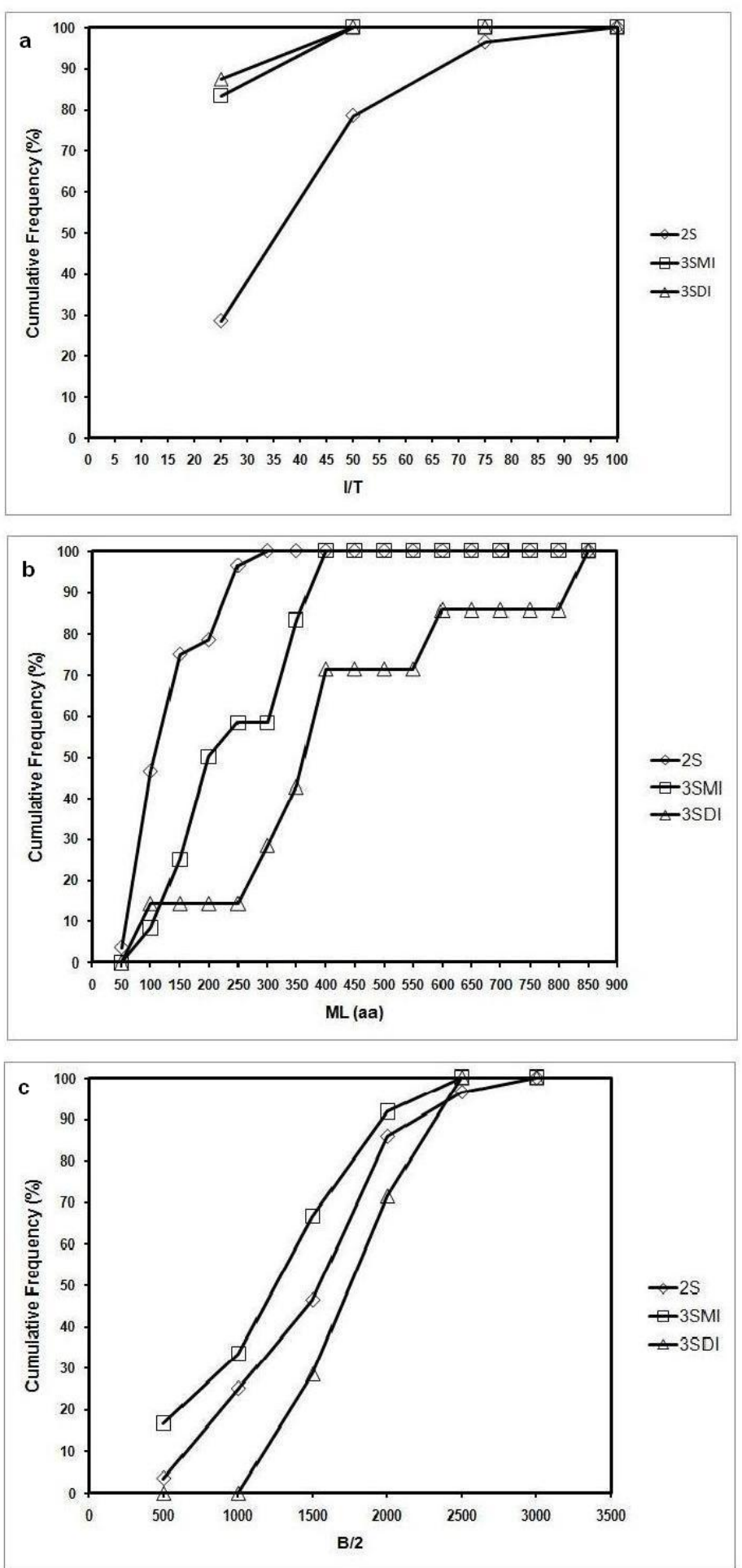

Figure 2: Percent cumulative frequency of $2 \mathrm{~S}$, 3SMI and 3SDI for ML, I/T and B/2 is given. (a) The distribution of the cumulative frequency of ML for 2S, 3SMI and 3SDI homodimers in the dataset is presented. About $90 \%$ of $2 \mathrm{~S}, 60 \%$ of 3SMI and $15 \%$ of $3 \mathrm{SDI}$ are covered when $\mathrm{ML}<=250$. Hence, $\mathrm{ML}<=250$ was selected as a decision condition in the development of the model. (b) The distribution of the cumulative frequency of I/T ratio for 2S, 3SMI and 3SDI homodimers in the dataset is presented. About $30 \%$ of $2 \mathrm{~S}$ and $90 \%$ of $3 \mathrm{SMI}$ and 3SDI are covered when $\mathrm{I} / \mathrm{T}<=25 \%$. Hence, $\mathrm{I} / \mathrm{T}<=25 \%$ was selected as a decision condition in the development of the model. (c) The distribution of the cumulative frequency of interface area for 2S, 3SMI and 3SDI homodimers in the dataset is presented. About 50\% of $2 \mathrm{~S}$, $70 \%$ of $3 \mathrm{SMI}$ and $30 \%$ of $3 \mathrm{SDI}$ are covered when $\mathrm{B} / 2<=1500$. Hence, $\mathrm{B} / 2<=1500$ was selected as a decision condition in the development of the model. 


\section{Discussion:}

Protein homodimer molecules have been defined as drug targets in cancer [48-49]. Thus, homodimers have commercial importance in drug discovery. The different folding mechanisms associated with homodimers are interesting and their study is often attractive. Homodimer denaturation experiments using fluorescence $[3,4, \mathbf{4}$, 13 -15, 19, 21-27, 30-43, 45, 46], circular dichroism [2, 3, 5-12, 14, 20, 26, 27, 29, 31-40, 43, 44], NMR [18] and adsorption [38] have been used to establish folding mechanism (2S, 3SMI, 3SDI) for a list of homodimers given in Table 1 (see supplementary material). This is time consuming, laborious and tedious. The number of homodimer structures with unknown folding mechanism is substantial [1]. Therefore, it is of interest to predict homodimer folding mechanism given their 3dimenisonal structures. A number of studies have been documented to relate folding and structura features [50-54]. We recently described the trends in parameters (monomer size, interface residues, interface area, hydrophobicity factor, hydrophilic residues and charged residues) for distinguishing 2S from 3S proteins [55]. However, no attempt has been made to predict their folding mechanism given their structures in complex state. Here, we describe a novel decision tree model using predictors $\mathrm{ML}, \mathrm{B} / 2$ and $\mathrm{I} / \mathrm{T}$ to predict folding mechanism (target variable) given their structures in complex state.

The decision tree model is developed based on the prevalence of weight associated with these predictors in a dataset of structures with known folding data (Figure 1). The distribution of its percent cumulative frequency of predictor variables in the datasets are given in Figures 2. Figure 2a gives percent cumulative frequency of 2S, 3SMI and 3SDI for ML. More than $90 \%$ of 2 S lie when ML $<=250$ When ML $=250$ only about $15 \%$ of 3SDI and $60 \%$ of 3SMI are covered. Hence, ML <=250 was selected as a decisive condition in the development of the model. Figure $\mathbf{2 b}$ gives percent cumulative frequency of 2S, 3SMI and 3SDI for I/T ratio. About $90 \%$ of 3SMI and 3SDI lie when $\mathrm{I} / \mathrm{T}<=25 \%$. When $\mathrm{I} / \mathrm{T}<=25 \%$, only about $30 \%$ of $2 \mathrm{~S}$ is covered. Therefore, $\mathrm{I} / \mathrm{T}<=25 \%$ was selected as a decision condition in the development of the model. Figure 2c gives percent cumulative frequency of $2 \mathrm{~S}, 3 \mathrm{SMI}$ and $3 \mathrm{SDI}$ for $\mathrm{B} / 2$. When $\mathrm{B} / 2<=$ 1500 , about $70 \%$ 3SMI, $50 \%$ 2S and 30\% 3SDI are covered. So, $\mathrm{B} / 2<=1500$ was selected as a decision condition in the development of the model. Thus, percent cumulative frequency values for predictors are used in the design and development of the decision tree model (Figure 3). The conditional values of the predictor variables are selected based on their biased cumulative frequency in the target categories (datasets). The decision tree model checks for predictor values within defined conditional values for multiple variables in a subsequent manner sequentially so as to reach the respective nodes to predict and assign target variables.

The decision tree model was applied to classify the dataset of 47 homodimers (with known folding data) in a cross validation experiment. The model produced the positive predictive values (PPV) $71.4 \%, 58.4 \%$ and $57.1 \%$ for 2 , 3SMI and 3SDI, respectively (Table 5 in supplementary material). We then extended the application of the decision tree model to a dataset of 149 homodimers with no folding data known. The model was able to assign folding data to 132 (88.5\%) of 149 structures to predicted target variables with only 17 structures unable to classify (Table 6 in supplementary material). This predicted data serves a framework to understand their folding mechanism given their structures. It should be noted that these predicted mechanism should be verified using denaturation experiments.

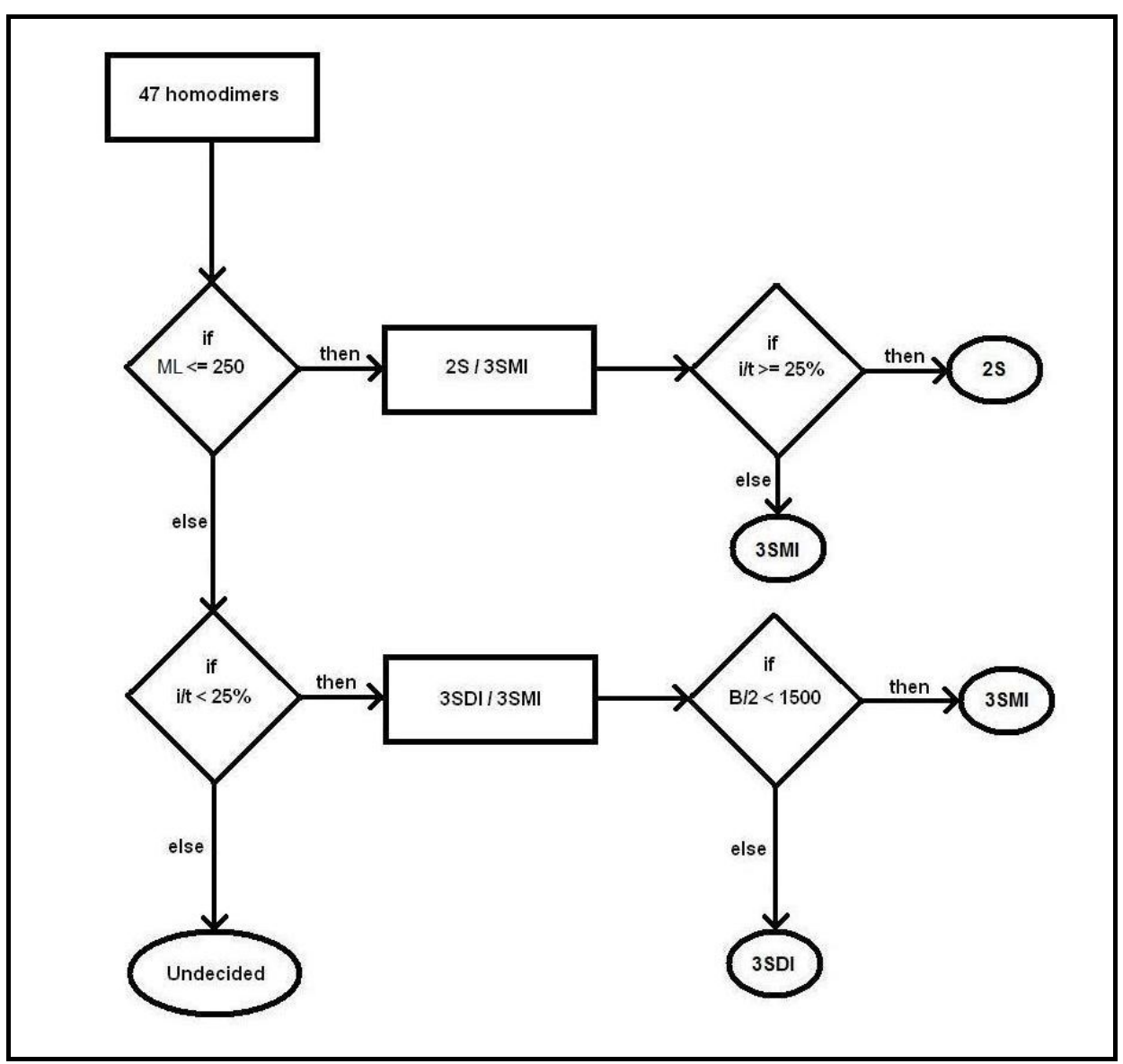

Figure 3: A flowchart describing the decision tree model is given. The decision tree model checks for predictor values within defined conditional values for multiple variables in a subsequent manner sequentially so as to reach the respective nodes to predict and assign target variables. 
Conclusion:

It was of interest to predict and classify the homodimer folding mechanism given their structures in complex state. A novel decision tree model is described using structural features (ML, B/2, I/T) derived from known structures to assign folding mechanism for homodimers given their structures. The decision tree model correctly classified with positive predictive values (PPV) $72 \%$ for 2S, $58 \%$ for 3 SMI and $57 \%$ for 3SDI into their respective groups in cross validation. Thus, the method finds application in grouping protein homodimer structures with unknown folding data. A number of homodimer structures with unknown folding information are available in PDB. We applied the model to a set of 149 homodimers with unknown folding data. The model classified 132 (88.5\% of 149) homodimers into 2S (39), 3SMI (61) and 3SDI (32). Consequently, a framework is established for these 132 known structures with predicted folding data for further experimental verification and confirmation.

Author's contribution:

PK conceived the idea and designed the experiment. VK and AS performed the analysis and summarized results. SL participated in the analysis and UK helped in manuscript preparation.

\section{Acknowledgement:}

VK, AS and SL wish to express their sincere thanks to all members of Biomedical Informatics for providing necessary support and material for the analysis. SL is a visitor to Biomedical Informatics.

References:

[1] C Zhanhua et al., Bioinformation 1: 28 (2005) [PMID: 17597849]

[2] TE Wales et al., Protein Sci. 13: 1918 (2004) [PMID: 15169951]

[3] JU Bowie, RT Sauer, Biochemistry 28: 7139 (1989) [PMID: 2819054]

[4] ME Milla, RT Sauer, Biochemistry 33: 1125 (1994) [PMID: 8110744]

[5] C Steif et al., Biochemistry 32: 3867 (1993) [PMID: [40] 8471599]

[6] R Jana et al., J Mol Biol. 273: 402 (1997) [PMID: 9344748]

[7] TB Topping, LM Gloss, J Mol Biol. 342: 247 (2004) [PMID: 15313621]

[8] YK Mok et al., Protein Sci. 5: 310 (1996) [PMID: 8745409]

[9] H Liang, TC Terwilliger, Biochemistry 30: 2772 (1991) [PMID: 2007116]

[10] J Ruiz-Sanz et al., Eur J Biochem. 271: 1497 (2004) [PMID: 15066175]

[11] TB Topping et al., J Mol Biol. 335: 1065 (2004) [PMID: 14698300]

[12] JR Stone et al., J Biol Chem. 277: 5448 (2002) [PMID: 11741982]

[13] SK Grant et al., Biochemistry 31: 9491 (1992) [PMID: 1390732]

[14] K Bajaj et al., Biochem J. 380: 409 (2004) [PMID:14763902]

[15] M Kretschmar, R Jaenicke, J Mol Biol. 291: 1147 (1999) [PMID: 10518950]

[16] CM Johnson et al., Biochemistry 31: 9717 (1992) [PMID: 1390748]

[17] A Tamura et al., J Mol Biol. 249: 636 (1995) [PMID: 7783216]

[18] LM Gloss et al., J Mol Biol. 312: 1121 (2001) [PMID: 11580254]

[19] DE Timm et al., Biochemistry 33: 4667 (1994) [PMID: 8161524]

[20] X Li et al., J Biol Chem. 272: 27324 (1997) [PMID: 9341182]

[21] D Kim et al., Protein Sci. 10: 741 (2001) [PMID:

11274465]

L D’Alfonso et al., Biochemistry 41: 326 (2002) [PMID:

11772032]

[23] HW Dirr, P Reinemer, Biochem Biophys

Res Commun. 180: 294 (1991) [PMID:

1930226]

[24] LA Wallace et al., Biochemistry 37: 5320 (1998)

[PMID: 9548764]

[25] W Kaplan et al., Protein Sci. 6: 399 (1997) [PMID: 9041642]

[26] N Ahmad et al., Biochemistry 37: 16765 (1998) [PMID: 9843447]

[27] V Mainfroid et al., J Mol Biol. 257: 441 (1996) [PMID: 8609635]

[28] ZW Yang et al., Protein Sci. 13: 830 (1994) [PMID: 14978314]

[29] J Ramstein et al., J Mol Biol. 331: 101 (2003) [PMID 12875839]

[30] L Zhu et al., J Mol Biol. 328: 235 (2003) [PMID: 12684011]

[31] JK Grimsley et al., Biochemistry 36: 14366 (1997) [PMID: 9398154]

[32] AC Clark et al., J Biol Chem. 268: 10773 (1993) [PMID: 8496144]

C Motono et al., Biochemistry 38: 1332 (1999) [PMID: 9930995]

[34] G Mei et al., Biochemistry 36: 10917 (1997)[ PMID: 9283082]

[35] SM Doyle et al., Biochemistry 39: 11667 (2000) [PMID: 10995234]

[36] MG Mateu J Mol Biol. 318: 519 (2002) [PMID: 12051856]

[37] R Ruller et al., Arch Biochem Biophys. 411: 112 (2003) [PMID: 12590929]

D Apiyo et al., Biochemistry 40: 4940 (2001) [PMID: 11305909]

F Malvezzi-Campeggi et al., Arch Biochem Biophys. 370: 201 (1999) [PMID: 10510278]

ME Stroppolo et al., Arch Biochem Biophys. 377: 215 (2000) [PMID: 10845696]

[41] J Malecki, Z Wasylewski, Eur J Biochem. 243: 660 (1997) [PMID: 9057829]

[42] A Aceto et al., Biochem J. 285: 241 (1992) [PMID:1637306]

[43] RS Gokhale et al., Biochemstry 35: 7150 (1996) [PMID: 8679542]

[44] YC Park, H Bedouelle, J Biol Chem. 273: 18052 (1998) [PMID: 9660761]

[45] P Wójciak et al., Int J Biol Macromol. 32: 43 (2003) [PMID: 12719131]

[46] Y Liang et al., J Biol Chem. 278: 30098 (2003) [PMID: 12771138]

[47] The United States Patent and Trademark Office database, USA

[48] T Tanaka et al., J Biol Che. 282: 29987 (2007) [PMID: 17656367]

[49] N Schülke et al., Proc Natl Acad Sci. 100: 12590 (2003) [PMID: 14583590]

[50] KE Neet, DE Timm, Protein Sci. 3: 2167 (1994) [PMID: 7756976]

[51] CJ Tsai, et al., Protein Sci. 6: 1793 (1997) [PMID: 9300480]

[52] Y Levy et al., Proc Natl Acad Sci. 101: 511 (2004) [PMID: 14694192]

[53] G Mei et al., Febs J. 272: 16 (2005) [PMID: 15634328]

[54] L Li et al., Bioinformation 1: 42 (2005) [PMID: 17597851]

[55] S Lulu et al., J Mol Graph Model. 28: 88 (2009) [PMID: 19442545]

[56] OV Tsodikov et al., J Comput Chem. 23: 600 (2002) [PMID: 11939594]

Edited by V. S. Mathura Citation: Suresh et al., Bioinformation 4(5): 197-205 (2009) License statement: This is an open-access article, which permits unrestricted use, distribution, and reproduction in any medium, for noncommercial purposes, provided the original author and source are credit. 


\section{Bioinformation}

\section{Supplementary material:}

Table 1: Dataset of 47 homodimer structures from PDB with known folding information

\begin{tabular}{|c|c|c|c|c|c|c|}
\hline PDB ID & Folding & ML (aa) & $\mathrm{B} / 2\left(\AA^{2}\right)$ & IR & $\mathbf{I} / \mathbf{T}$ & Folding Reference \# \\
\hline $2 \mathrm{cpg}$ & $2 S$ & 45 & 1632 & 24 & 71 & [2] \\
\hline 1 arq & $2 \mathrm{~s}$ & 53 & 2007 & 42 & 80 & [3] \\
\hline 1arr & $2 S$ & 53 & 1962 & 30 & 75 & [4] \\
\hline 1rop & $2 S$ & 63 & 1345 & 34 & 54 & [5] \\
\hline 5cro & $2 S$ & 66 & 648 & 16 & 29 & [6] \\
\hline $1 \mathrm{bfm}$ & $2 S$ & 69 & 1593 & 40 & 60 & [7] \\
\hline $1 \mathrm{a} 7 \mathrm{~g}$ & $2 S$ & 82 & 918 & 44 & 32 & [8] \\
\hline $1 \mathrm{vqb}$ & $2 S$ & 87 & 850 & 47 & 26 & [9] \\
\hline $1 b 8 z$ & $2 S$ & 90 & 1894 & 19 & 53 & [10] \\
\hline 1ety & $2 S$ & 98 & 2079 & 36 & 49 & [11] \\
\hline $1 y 7 q$ & $2 S$ & 98 & 1508 & 40 & 43 & [12] \\
\hline 1a8g & $2 S$ & 99 & 1785 & 31 & 44 & [12] \\
\hline 1siv & $2 S$ & 99 & 1684 & 28 & 42 & [13] \\
\hline 1vub & $2 S$ & 101 & 1074 & 18 & 29 & [14] \\
\hline 1hdf & $2 \mathrm{~s}$ & 102 & 156 & 5 & 6 & [15] \\
\hline $1 \mathrm{cmb}$ & $2 S$ & 104 & 1813 & 42 & 38 & [16] \\
\hline 3ssi & $2 S$ & 108 & 866 & 38 & 29 & [17] \\
\hline 1wrp & $2 S$ & 108 & 2243 & 39 & 48 & [18] \\
\hline 1bet & $2 S$ & 107 & 1366 & 41 & 42 & [19] \\
\hline 1buo & $2 S$ & 121 & 1972 & 50 & 41 & [20] \\
\hline 1oh0 & $2 S$ & 131 & 1036 & 53 & 24 & [21] \\
\hline 1beb & $2 \mathrm{~s}$ & 162 & 527 & 15 & 10 & [22] \\
\hline $2 \mathrm{gsr}$ & $2 S$ & 207 & 1331 & 49 & 18 & [23] \\
\hline 1gsd & $2 S$ & 208 & 1477 & 52 & 18 & [24] \\
\hline 1 gta & $2 S$ & 218 & 1505 & 51 & 21 & [25] \\
\hline 2bqp & $2 S$ & 234 & 955 & 47 & 41 & [26] \\
\hline 1hti & $2 S$ & 248 & 1685 & 46 & 18 & [27] \\
\hline 1ee1 & $2 \mathrm{~S}$ & 271 & 2507 & 48 & 23 & [28] \\
\hline $1 \mathrm{mul}$ & 3SDI & 90 & 1739 & 25 & 50 & [29] \\
\hline 1hqo & 3SDI & 258 & 1656 & 31 & 20 & [30] \\
\hline $1 p s c$ & 3SDI & 329 & 1353 & 25 & 12 & [31] \\
\hline 1luc & 3SDI & 355 & 2072 & 52 & 17 & [32] \\
\hline $1 \mathrm{~cm} 7$ & 3SDI & 363 & 2317 & 43 & 16 & [33] \\
\hline 1aoz & 3SDI & 552 & 1817 & 9 & 5 & [34] \\
\hline 1nl3 & 3SDI & 835 & 1351 & 20 & 5 & [35] \\
\hline $1 \mathrm{a} 43$ & 3SMI & 72 & 921 & 22 & 44 & [36] \\
\hline 1qll & 3SMI & 121 & 432 & 6 & 12 & [37] \\
\hline $1 \mathrm{df} x$ & 3SMI & 125 & 1472 & 17 & 34 & [38] \\
\hline 1yai & 3SMI & 151 & 309 & 6 & 9 & [39] \\
\hline 1spd & 3SMI & 154 & 658 & 13 & 13 & [40] \\
\hline 1run & 3SMI & 197 & 1542 & 22 & 21 & [41] \\
\hline 11gs & 3SMI & 209 & 1197 & 19 & 17 & [42] \\
\hline $2 \mathrm{tdm}$ & 3SMI & 316 & 2332 & 63 & 20 & [43] \\
\hline 1tya & 3SMI & 319 & 1513 & 23 & 13 & [44] \\
\hline 1cvi & 3SMI & 342 & 1444 & 37 & 13 & [44] \\
\hline 1nd5 & 3SMI & 354 & 1512 & 31 & 12 & [45] \\
\hline $2 \mathrm{crk}$ & 3SMI & 381 & 1119 & 30 & 11 & [46] \\
\hline
\end{tabular}

Table 2: The minimum, maximum, mean and standard deviation value of the predictor variables is given for 47 homodimers.

\begin{tabular}{lllll}
\hline Parameters & Min & Max & mean & S.D \\
\hline Length & 45 & 835 & 190.5 & 148.8 \\
B/2 & 156 & 2507 & 1429.2 & 550.7 \\
I/T (\%) & 5 & 80 & 30 & 19 \\
IR & 6 & 96 & 40 & 15 \\
\hline
\end{tabular}

Table 3: An assignment dataset of 149 homodimers with unknown folding data.

\begin{tabular}{cccccc}
\hline Folding & $\#$ & \multicolumn{3}{c}{ Result } & PPV \\
& & TP & FP & UD & \\
\hline 2S & 28 & 20 & 8 & 0 & $71.4 \%$ \\
3SMI & 12 & 7 & 5 & 0 & $58.4 \%$ \\
3SDI & 7 & 4 & 3 & 0 & $57.1 \%$ \\
\hline
\end{tabular}




\section{Bioinformation}

Table 4: The minimum, maximum, mean and standard deviation value of the predictor variables is given for 149 homodimers of the assignment dataset.

\begin{tabular}{|c|c|c|c|c|c|}
\hline PDB & Assigned Folding & ML & $\mathrm{B} / 2$ & IR & $\mathbf{I} / \mathbf{T}$ \\
\hline $1 \mathrm{~A} 4 \mathrm{I}$ & 3SMI & 285 & 1435.8 & 39 & 0.14 \\
\hline $1 \mathrm{~A} 4 \mathrm{U}$ & UD & 254 & 2621.6 & 67 & 0.26 \\
\hline 1AA7 & 3SMI & 158 & 1170.4 & 28 & 0.18 \\
\hline $1 \mathrm{AD} 1$ & 3SDI & 264 & 1531.2 & 38 & 0.14 \\
\hline $1 \mathrm{ADE}$ & 3SDI & 431 & 3206.6 & 98 & 0.23 \\
\hline 1AFW & 3SDI & 390 & 2545.3 & 69 & 0.18 \\
\hline 1ALK & UD & 449 & 4042.7 & 112 & 0.25 \\
\hline 1AOR & 3SMI & 605 & 1293.9 & 36 & 0.06 \\
\hline 1AQ6 & 3SMI & 245 & 2241.7 & 55 & 0.22 \\
\hline $1 \mathrm{AUO}$ & 3SMI & 218 & 694.76 & 22 & 0.1 \\
\hline $1 \mathrm{BBH}$ & 3SMI & 131 & 794.11 & 23 & 0.18 \\
\hline 1BH5 & $2 S$ & 177 & 3969.4 & 105 & 0.59 \\
\hline 1BJW & 3SDI & 381 & 2864.5 & 79 & 0.21 \\
\hline 1BMD & 3SDI & 327 & 1659.5 & 43 & 0.13 \\
\hline $1 \mathrm{BXG}$ & 3SMI & 349 & 1154.8 & 30 & 0.08 \\
\hline $1 \mathrm{C} 6 \mathrm{X}$ & $2 \mathrm{~S}$ & 99 & 1852.1 & 46 & 0.46 \\
\hline $1 \mathrm{CBK}$ & 3SMI & 160 & 972.67 & 30 & 0.18 \\
\hline 1CDC & $2 \mathrm{~S}$ & 96 & 3980.4 & 86 & 0.89 \\
\hline $1 \mathrm{CHM}$ & UD & 401 & 3789.2 & 105 & 0.26 \\
\hline $1 \mathrm{CNZ}$ & 3SDI & 363 & 2549 & 64 & 0.18 \\
\hline $1 \mathrm{COZ}$ & 3SMI & 126 & 1100.3 & 29 & 0.23 \\
\hline 1CQS & $2 \mathrm{~S}$ & 124 & 1067 & 31 & 0.25 \\
\hline $1 \mathrm{D} 1 \mathrm{G}$ & $2 S$ & 164 & 1647.9 & 44 & 0.27 \\
\hline 1DOR & 3SDI & 311 & 2314.6 & 60 & 0.19 \\
\hline $1 \mathrm{DPG}$ & 3SDI & 485 & 2369.9 & 65 & 0.13 \\
\hline 1DQP & 3SMI & 230 & 1827 & 53 & 0.23 \\
\hline 1DQT & 3SMI & 117 & 902.69 & 27 & 0.23 \\
\hline 1DVJ & 3SMI & 239 & 315.72 & 11 & 0.05 \\
\hline $1 \mathrm{EAJ}$ & 3SMI & 124 & 760.89 & 26 & 0.21 \\
\hline 1EBL & 3SDI & 309 & 2364.2 & 67 & 0.22 \\
\hline $1 \mathrm{EHI}$ & 3SDI & 360 & 2714.4 & 74 & 0.2 \\
\hline $1 \mathrm{EKP}$ & 3SDI & 365 & 2461.4 & 69 & 0.19 \\
\hline 1EN5 & 3SMI & 205 & 880.59 & 24 & 0.12 \\
\hline 1EN7 & $2 S$ & 157 & 3444.1 & 75 & 0.48 \\
\hline $1 \mathrm{EOG}$ & 3SMI & 208 & 1214.3 & 33 & 0.16 \\
\hline $1 \mathrm{EXQ}$ & $2 \mathrm{~S}$ & 147 & 1650.4 & 47 & 0.32 \\
\hline 1EYV & 3SMI & 131 & 1165.5 & 28 & 0.21 \\
\hline $1 \mathrm{EZ2}$ & 3SMI & 328 & 1412 & 34 & 0.1 \\
\hline $1 \mathrm{~F} 13$ & $2 \mathrm{~S}$ & 161 & 2050.4 & 48 & 0.3 \\
\hline $1 \mathrm{~F} 17$ & 3SDI & 722 & 2802.6 & 92 & 0.13 \\
\hline $1 F 4 Q$ & 3SDI & 293 & 1704.9 & 43 & 0.15 \\
\hline $1 \mathrm{~F} 89$ & 3SMI & 271 & 1475.3 & 36 & 0.13 \\
\hline 1FC5 & 3SDI & 397 & 2928 & 85 & 0.21 \\
\hline $1 \mathrm{FJH}$ & $2 S$ & 236 & 2093 & 58 & 0.25 \\
\hline 1FL1 & 3SMI & 192 & 1322 & 42 & 0.22 \\
\hline 1FP3 & 3SMI & 402 & 1240.1 & 33 & 0.08 \\
\hline 1FUX & 3SMI & 164 & 877.71 & 25 & 0.15 \\
\hline 1FWL & 3SDI & 296 & 1504.3 & 43 & 0.14 \\
\hline 1FYD & UD & 271 & 2692.4 & 69 & 0.25 \\
\hline $1 \mathrm{G} 0 \mathrm{~S}$ & $2 S$ & 201 & 3947.1 & 96 & 0.48 \\
\hline $1 \mathrm{G} 1 \mathrm{~A}$ & 3SMI & 352 & 1388.5 & 45 & 0.13 \\
\hline $1 \mathrm{G} 1 \mathrm{M}$ & 3SDI & 287 & 1866.7 & 54 & 0.19 \\
\hline $1 \mathrm{G} 64$ & 3SMI & 241 & 936.99 & 26 & 0.11 \\
\hline $1 \mathrm{G} 8 \mathrm{~T}$ & $2 \mathrm{~S}$ & 169 & 2509.2 & 62 & 0.37 \\
\hline 1GD7 & $2 S$ & 109 & 1681.2 & 43 & 0.39 \\
\hline 1GGQ & $2 S$ & 162 & 2193.2 & 58 & 0.35 \\
\hline $1 \mathrm{H} 8 \mathrm{X}$ & $2 \mathrm{~S}$ & 107 & 1781.7 & 49 & 0.46 \\
\hline $1 \mathrm{HJ} 3$ & 3SMI & 91 & 70.29 & 4 & 0.04 \\
\hline 1HJR & 3SMI & 158 & 503.45 & 16 & 0.1 \\
\hline 1HSJ & 3SMI & 487 & 2167.2 & 56 & 0.11 \\
\hline $1 \mathrm{HSS}$ & $2 \mathrm{~S}$ & 111 & 1161.9 & 32 & 0.28 \\
\hline $1 \mathrm{IOR}$ & $2 \mathrm{~S}$ & 162 & 2277.3 & 65 & 0.4 \\
\hline $1 \mathrm{I} 4 \mathrm{~S}$ & 3SMI & 147 & 1130.8 & 30 & 0.2 \\
\hline $1 \mathrm{I} 8 \mathrm{~T}$ & 3SMI & 367 & 1267.9 & 42 & 0.11 \\
\hline 1IPI & $2 \mathrm{~S}$ & 114 & 1035.6 & 30 & 0.26 \\
\hline 1IRI & UD & 557 & 6766.2 & 180 & 0.32 \\
\hline $1 \mathrm{~J} 30$ & $2 \mathrm{~S}$ & 141 & 3351.4 & 84 & 0.59 \\
\hline 1JD0 & 3SMI & 260 & 1229.1 & 38 & 0.15 \\
\hline 1JFL & 3SMI & 228 & 1363.9 & 40 & 0.17 \\
\hline
\end{tabular}

ISSN 0973-2063 (online) 0973-8894 (print) 


\section{Bioinformation}

\begin{tabular}{|c|c|c|c|c|c|}
\hline $1 \mathrm{JMV}$ & 3SMI & 140 & 1233.1 & 32 & 0.23 \\
\hline 1JOG & $2 \mathrm{~S}$ & 129 & 1121.9 & 33 & 0.25 \\
\hline 1JP3 & 3SMI & 210 & 1793.9 & 44 & 0.21 \\
\hline 1JR8 & $2 \mathrm{~S}$ & 105 & 1281.4 & 33 & 0.31 \\
\hline 1JV3 & 3SMI & 490 & 1498.2 & 83 & 0.17 \\
\hline 1JYS & 3SMI & 226 & 1287.8 & 37 & 0.16 \\
\hline $1 \mathrm{~K} 3 \mathrm{~S}$ & $2 \mathrm{~S}$ & 106 & 1148.7 & 31 & 0.29 \\
\hline $1 \mathrm{~K} 6 \mathrm{Z}$ & $2 S$ & 120 & 1402.7 & 36 & 0.3 \\
\hline $1 \mathrm{KGN}$ & UD & 296 & 2754 & 73 & 0.25 \\
\hline $1 \mathrm{KIY}$ & 3SDI & 354 & 2888.7 & 73 & 0.2 \\
\hline $1 \mathrm{KSO}$ & $2 S$ & 93 & 1749.7 & 42 & 0.45 \\
\hline 1L5B & $2 \mathrm{~S}$ & 101 & 3252.3 & 80 & 0.79 \\
\hline 1L5X & UD & 270 & 3016.1 & 73 & 0.27 \\
\hline 1LBQ & 3SDI & 356 & 1639 & 51 & 0.14 \\
\hline $1 \mathrm{LHP}$ & 3SDI & 306 & 2158.8 & 56 & 0.18 \\
\hline 1LHZ & $2 \mathrm{~S}$ & 213 & 1759.3 & 58 & 0.27 \\
\hline 1LK9 & UD & 425 & 4614 & 112 & 0.26 \\
\hline 1LNW & $2 S$ & 137 & 1247.2 & 52 & 0.38 \\
\hline 1LQ9 & $2 S$ & 112 & 1650.1 & 46 & 0.41 \\
\hline 1M3E & 3SDI & 459 & 2650.1 & 71 & 0.15 \\
\hline $1 \mathrm{M} 4 \mathrm{I}$ & 3SMI & 181 & 1327.7 & 40 & 0.22 \\
\hline 1M6P & 3SMI & 146 & 1095.9 & 35 & 0.24 \\
\hline $1 \mathrm{M} 7 \mathrm{H}$ & $2 \mathrm{~S}$ & 203 & 2020.7 & 50 & 0.25 \\
\hline 1M98 & 3SDI & 400 & 2891.8 & 74 & 0.19 \\
\hline $1 \mathrm{M} 9 \mathrm{~K}$ & 3SMI & 316 & 1252.2 & 41 & 0.13 \\
\hline $1 \mathrm{MI} 3$ & 3SMI & 319 & 1301.1 & 38 & 0.12 \\
\hline $1 \mathrm{MJH}$ & 3SMI & 143 & 1089.5 & 29 & 0.2 \\
\hline $1 \mathrm{MKB}$ & $2 \mathrm{~S}$ & 171 & 1809 & 54 & 0.31 \\
\hline 1MNA & 3SMI & 276 & 831.41 & 23 & 0.08 \\
\hline 1N80 & 3SDI & 328 & 2606.7 & 74 & 0.22 \\
\hline 1NA8 & 3SMI & 151 & 60.86 & 17 & 0.11 \\
\hline 1NFZ & 3SMI & 176 & 857.63 & 23 & 0.13 \\
\hline 1NU6 & 3SDI & 728 & 2342.6 & 65 & 0.09 \\
\hline 1NW1 & 3SMI & 365 & 1249.1 & 34 & 0.09 \\
\hline 1NWW & $2 \mathrm{~S}$ & 145 & 1605 & 42 & 0.29 \\
\hline 1NY5 & UD & 384 & 3997.8 & 108 & 0.28 \\
\hline $1 \mathrm{OAC}$ & UD & 719 & 8022.8 & 221 & 0.31 \\
\hline 1ON2 & 3SMI & 135 & 1311.4 & 32 & 0.23 \\
\hline $1 \mathrm{OR} 4$ & $2 \mathrm{~S}$ & 169 & 1933.5 & 44 & 0.26 \\
\hline $1 \mathrm{ORO}$ & 3SMI & 213 & 1292.4 & 38 & 0.18 \\
\hline 1OTV & 3SDI & 254 & 2298.4 & 60 & 0.23 \\
\hline $10 \times 8$ & 3SMI & 105 & 748.72 & 20 & 0.19 \\
\hline 1P3W & 3SDI & 385 & 2473.3 & 74 & 0.19 \\
\hline $1 \mathrm{P} 43$ & UD & 436 & 1965.6 & 324 & 0.74 \\
\hline 1PE0 & 3SMI & 187 & 1369.1 & 35 & 0.19 \\
\hline 1PJQ & UD & 447 & 6479 & 162 & 0.36 \\
\hline 1PNO & UD & 652 & 13103 & 258 & 0.39 \\
\hline 1PN2 & 3SMI & 269 & 1158.7 & 31 & 0.11 \\
\hline 1PP2 & $2 \mathrm{~S}$ & 122 & 1447.7 & 42 & 0.34 \\
\hline 1PT5 & UD & 415 & 6455 & 167 & 0.4 \\
\hline 1Q8R & 3SMI & 118 & 710.02 & 20 & 0.17 \\
\hline 1QFH & $2 \mathrm{~S}$ & 212 & 2441 & 64 & 0.3 \\
\hline $1 \mathrm{QHI}$ & 3SDI & 304 & 1790.8 & 53 & 0.17 \\
\hline $1 \mathrm{QMJ}$ & 3SMI & 132 & 609.43 & 17 & 0.13 \\
\hline 1QR2 & $2 \mathrm{~S}$ & 230 & 2036.3 & 57 & 0.25 \\
\hline 1QXR & $2 \mathrm{~S}$ & 187 & 1874 & 48 & 0.26 \\
\hline 1QYA & 3SMI & 293 & 1058.1 & 30 & 0.1 \\
\hline 1R5P & $2 \mathrm{~S}$ & 90 & 808.02 & 24 & 0.27 \\
\hline 1R7A & 3SMI & 503 & 1035.7 & 34 & 0.07 \\
\hline 1R8J & UD & 272 & 3656 & 91 & 0.33 \\
\hline 1R9C & $2 \mathrm{~S}$ & 125 & 2022.8 & 56 & 0.45 \\
\hline 1REG & 3SMI & 122 & 690.85 & 19 & 0.16 \\
\hline 1RVE & 3SMI & 244 & 1605.3 & 46 & 0.19 \\
\hline 1RYA & 3SMI & 160 & 1335.5 & 38 & 0.23 \\
\hline 1S44 & 3SMI & 180 & 1198.9 & 34 & 0.19 \\
\hline 1SCF & 3SMI & 116 & 875.37 & 22 & 0.19 \\
\hline 1SMT & $2 \mathrm{~S}$ & 98 & 2030.2 & 52 & 0.53 \\
\hline $1 \mathrm{SOX}$ & 3SDI & 463 & 1574.3 & 51 & 0.11 \\
\hline $1 \mathrm{TLU}$ & 2S & 117 & 1503.8 & 44 & 0.37 \\
\hline 1TRK & 3SDI & 678 & 4826.6 & 130 & 0.19 \\
\hline 1UC8 & 3SDI & 254 & 1946.4 & 52 & 0.2 \\
\hline $2 \mathrm{DAB}$ & 3SDI & 280 & 2406.4 & 63 & 0.22 \\
\hline 2GSA & UD & 427 & 5178.7 & 146 & 0.34 \\
\hline 2HHM & 3SDI & 266 & 1818.7 & 57 & 0.21 \\
\hline
\end{tabular}

ISSN 0973-2063 (online) 0973-8894 (print) 


\section{Bioinformation}

\begin{tabular}{lccccc}
\hline 2NAC & UD & 374 & 3896 & 103 & 0.27 \\
3LYN & 3SMI & 122 & 1014.5 & 25 & 0.2 \\
3SDH & 3SMI & 145 & 950.3 & 27 & 0.19 \\
7AAT & 3SDI & 401 & 3426.8 & 97 & 0.24 \\
8PRK & 3SMI & 282 & 1015.1 & 27 & 0.09 \\
9WGA & 3SMI & 170 & 248.23 & 14 & 0.08 \\
\hline
\end{tabular}

Table 5: Cross validation experiment positive predictive values (PPV) of the decision tree model when applied to the dataset of 47 homodimers.

\begin{tabular}{lllll}
\hline Parameters & Min & Max & Avg & S.D \\
\hline Length & 90 & 728 & 259.8 & 142.5 \\
B/2 & 60.8 & 13103.3 & 2049.8 & 1567.1 \\
I/T (\%) & 4 & 89 & 24 & 13 \\
IR & 3 & 324 & 57 & 43.1 \\
\hline
\end{tabular}

\begin{tabular}{|c|c|c|c|c|c|c|c|c|c|c|c|}
\hline \multirow[t]{4}{*}{$2 S$} & 39 & 1BH5 & $1 \mathrm{C} 6 \mathrm{X}$ & $1 \mathrm{CDC}$ & $1 \mathrm{CQS}$ & $1 \mathrm{D} 1 \mathrm{G}$ & 1EN7 & $1 \mathrm{EXQ}$ & $1 \mathrm{~F} 4 \mathrm{Q}$ & $1 \mathrm{FJH}$ & $1 \mathrm{G} 0 \mathrm{~S}$ \\
\hline & & $1 \mathrm{G} 64$ & 1GD7 & 1GGQ & $1 \mathrm{H} 8 \mathrm{X}$ & 1HSS & $1 \mathrm{IOR}$ & 1IPI & 1J30 & $1 \mathrm{JOG}$ & 1JR8 \\
\hline & & 1K35 & $1 \mathrm{~K} 6 \mathrm{Z}$ & $1 \mathrm{KSO}$ & 1L5B & $1 \mathrm{LHZ}$ & $1 \mathrm{LNW}$ & 1LQ9 & $1 \mathrm{M} 7 \mathrm{H}$ & $1 \mathrm{MKB}$ & 1NWW \\
\hline & & 1OR4 & 1PP2 & 1QFH & 1QR2 & 1QXR & 1R5P & 1R9C & 1SMT & 1TLU & \\
\hline \multirow[t]{7}{*}{ 3SMI } & 61 & $1 \mathrm{~A} 41$ & 1AA7 & $1 \mathrm{AOR}$ & 1AQ6 & $1 \mathrm{AUO}$ & $1 \mathrm{BBH}$ & $1 \mathrm{BXG}$ & $1 \mathrm{CBK}$ & $1 \mathrm{COZ}$ & $1 \mathrm{DQP}$ \\
\hline & & 1DQT & $1 \mathrm{DVJ}$ & $1 \mathrm{EAJ}$ & 1EN5 & $1 \mathrm{EOG}$ & $1 \mathrm{EYV}$ & $1 \mathrm{EZ2}$ & $1 F 89$ & 1FL1 & 1FP3 \\
\hline & & 1FUX & $1 \mathrm{G} 1 \mathrm{~A}$ & $1 \mathrm{G} 8 \mathrm{~T}$ & $1 \mathrm{HJ} 3$ & $1 \mathrm{HJR}$ & $1 \mathrm{HSJ}$ & $1 \mathrm{I} 4 \mathrm{~S}$ & $1 \mathrm{I} 8 \mathrm{~T}$ & $1 \mathrm{JDO}$ & 1JFL \\
\hline & & $1 \mathrm{JMV}$ & 1JP3 & 1JV3 & 1JYS & $1 \mathrm{M} 4 \mathrm{I}$ & 1M6P & 1M98 & $1 \mathrm{MI} 3$ & $1 \mathrm{MJH}$ & 1MNA \\
\hline & & 1NA8 & $1 \mathrm{NFZ}$ & 1NW1 & $10 N 2$ & $10 R O$ & $10 \times B$ & 1PEO & 1PN2 & 1Q8R & 1QMJ \\
\hline & & 1QYA & 1R7A & $1 \mathrm{REG}$ & 1RVE & $1 \mathrm{RYA}$ & $1 \mathrm{~S} 44$ & $1 \mathrm{SCF}$ & $3 \mathrm{LYN}$ & $3 \mathrm{SDH}$ & 8PRK \\
\hline & & 9WGA & & & & & & & & & \\
\hline \multirow[t]{4}{*}{ 3SDI } & 32 & 1AD1 & $1 \mathrm{ADE}$ & 1AFW & 1BJW & 1BMD & 1CNZ & 1DOR & $1 \mathrm{DPG}$ & 1EBL & $1 \mathrm{EHI}$ \\
\hline & & $1 \mathrm{EKP}$ & $1 F 13$ & $1 \mathrm{~F} 17$ & $1 \mathrm{FCS}$ & 1FWL & $1 \mathrm{G} 1 \mathrm{M}$ & $1 \mathrm{KIY}$ & $1 \mathrm{LBQ}$ & $1 \mathrm{LHP}$ & $1 \mathrm{M} 3 \mathrm{E}$ \\
\hline & & $1 \mathrm{M} 9 \mathrm{~K}$ & $1 \mathrm{~N} 80$ & 1NU6 & $10 T V$ & 1P3W & $1 \mathrm{QHI}$ & $1 \mathrm{SOX}$ & 1TRK & 1UC8 & $2 \mathrm{DAB}$ \\
\hline & & 2HHM & 7AAT & & & & & & & & \\
\hline \multirow[t]{2}{*}{ UD } & 17 & $1 \mathrm{~A} 4 \mathrm{U}$ & $1 \mathrm{ALK}$ & 1CHM & 1FYD & 1IRI & $1 \mathrm{KGN}$ & $1 \mathrm{~L} 5 \mathrm{X}$ & 1LK9 & 1NY5 & $10 A C$ \\
\hline & & $1 \mathrm{P} 43$ & $1 \mathrm{PJQ}$ & 1PN0 & 1PT5 & $1 \mathrm{R} 8 \mathrm{~J}$ & 2GSA & 2NAC & & & \\
\hline
\end{tabular}

